\title{
Narrated Video Clips Improve Student Learning
}

\author{
Philip J. Stephens ${ }^{1, *}$ \\ ${ }^{1}$ Department of Biology, Villanova University, Villanova, USA \\ *Correspondence: Department of Biology, Villanova University, Villanova, PA 19085, USA. Tel: 1-610-519-4839. \\ E-mail: phil.stephens@villanova.edu
}

Received: April 4, 2017

Accepted: May 3, 2017 Online Published: June 6, 2017

doi:10.5430/wje.v7n3p14

URL: https://doi.org/10.5430/wje.v7n3p14

\begin{abstract}
The purpose of this study is to determine whether viewing narrated video clips improves student learning. The study was conducted with undergraduate, mostly Biology majors, in an Animal Physiology course held in successive semesters. When both classes were given the same face-to-face lectures and identical online resources their performance on an exam with the same multiple choice questions was not statistically different (two-tailed, unpaired t-test). However, when one group was also given unlimited online access to narrated video clips, these students performed statistically better on a second exam with identical multiple choice questions. An attitudinal survey showed that students used the video clips as an introduction to the interactive animations and simulations and as standalone mini-lectures, and they indicated that viewing the clips was the best and most efficient way to learn physiological concepts. While this study used narrated video clips to augment traditional face-to-face instruction, they could be used in a flipped-class, a blended class, and for distance learning.
\end{abstract}

Keywords: animation; simulation; narrated video clip; learning; physiology; concept

\section{Introduction}

Cognitive learning theory maintains that new information travels through auditory and visual channels and enters working (or short-term) memory, where it is organized and transferred to long term memory (Moreno \& Mayer, 1999; Mayer, 2001). During this transfer process links are created between new and established knowledge so that the information can be placed in context for retrieval at a later date. Unfortunately, the rapid increase in our knowledge often tempts instructors to pack their courses with new content (Knight \& Wood, 2005; Lujan \& DiCarlo, 2005). Since the capacity of each sensory channel is both limited and finite, some instructors resort to simply telling students what they need to know to prevent cognitive overload (Sweller, 2005). Students, in turn, when faced with large volumes of facts often commit them to short-term memory since they have little time or motivation to transfer this huge amount of new knowledge into long term memory. Under these circumstances students often do not retain the knowledge in the long term, do not acquire a deep understanding of the subject, and fail to develop life-long skills such as critical thinking, problem solving, and communication.

If multimedia learning involves conveying information through auditory and visual channels (Mayer, 2001), it seems reasonable that learning may be enhanced by using narrated video clips which allow students to watch moving images while simultaneously listening to the synchronized commentary (Kozma, 1991; Clark \& Mayer, 2003). Studies of undergraduate physiology students showed that, while male and female students have different sensory modality preferences (Wehrwein, Lujan \& DiCarlo, 2007), more prefer visual learning (46\% females and $49 \%$ males) (Dobson, 2009). It would seem, therefore, that physiology students may be good candidates to examine whether a multimedia approach will improve learning. The present study focused on an undergraduate physiology course and involved the development of 24 interactive animations and simulations using Adobe ${ }^{\circledR}$ Flash $^{\circledR}$ software. These animations and simulations were used during face-to-face lectures to demonstrate a range of physiological concepts and were made available through the course website for student use in their own time. Feedback from students taking the course in previous semesters revealed that many did not recall sufficient details to repeat the demonstrations seen in lecture. Therefore, a series of narrated video clips were developed to illustrate how students could interact with the online animations and simulations and, again, were made available to the students through the course website. The learning outcomes from this class were compared with those seen in the previous semester, when only the animations 
and simulations were available, to determine whether the narrated video clips improved student learning.

\section{Methods}

\subsection{Context}

The Biology Department at Villanova University offers an undergraduate course in Animal Physiology. This elective course is run every semester as a single lecture section and 2 or 3 lab sections, each with 18 students. The number of lab sections offered in any one semester, and therefore the number of students in the class, is determined by administration, not by the instructor. This study was conducted over two semesters using two groups of students; 50 students (60\% female) completed the course in fall 2015 and 35 (66\% female) students finished the course in spring 2016. The students in the two classes were all undergraduate science majors, and $88 \%$ were biology majors. All students in the study were given the same lectures and online resources but those in the spring were also given access to narrated video clips for the material on one exam.

The course website is divided into several sections including:

1. Lectures The notes for each lecture are presented in HTML and WORD format. The HTML file is used for lecture and the mp3 recording of the lecture was subsequently integrated into the HTML notes so that students can listen to the original lecture again and follow the notes, the figures and the interactive animations and simulations in their own time.

2. Exams. Students in the course take three exams, each of which covers about one-third of the course, and a final cumulative exam. In this study, permission was obtained from administration to give the same exams (1 and 2) to the two classes. Each of these exams was taken in a lecture time slot at the university test-taking facility. Each exam was composed of twenty-seven multiple choice questions and six questions which required a short typed answer. Answers from the multiple choice questions were graded by software within the Learning Management System $\left(\right.$ Blackboard $^{\circledR}$ ) while the typed answers were graded by the instructor. The grading of the typed answers were considered to be subjective so were excluded from the data analysis.

\subsection{Narrated Video Clips}

A total of 24 interactive Adobe ${ }^{\circledR}$ Flash $^{\circledR}$ animations were developed in the areas of nerve, endocrine and sensory physiology and were used in lectures to explain certain fundamental principles and concepts. Camtasia ${ }^{\circledR}$ software $\left(\right.$ TechSmith $^{\circledR}$ ) was used to produce a video clip of each animation or simulation using embedded screen capture. A scripted narration was recorded for each clip using a microphone connected to a digital voice recorder and the resulting audio file was inserted into the timeline to produce a narrated video clip. In this way, a pair of files was produced: an interactive animation or simulation and a narrated video clip. These files were placed on the course website immediately after the lecture in which the concept was explained so that the students in the spring 2016 course had unlimited online access. Access to these files was established through links on the home page and the Learning Management System tracked the number of hits for each file on a daily basis.

Links to three pairs of narrated video clips and interactive animations are listed in Appendix I.

\subsection{Outcomes Analysis}

Analysis was performed by analyzing student performance on two exams:

Exam 1: The same exam was given to the fall 2015 and spring 2016 classes but neither was given access to narrated video clips.

Exam 2: The same exam was given to the fall 2015 and spring 2016 classes but the latter had unlimited access to the 24 narrated video clips.

In both classes, one week prior to the exam the same practice exam (from spring 2015) was posted and represented as the exam from the previous semester.

An online survey was given to the spring 2016 class to gather feedback on their use of the narrated video clips. 
Table 1. The mean scores (and standard deviation values) for 27 multiple-choice questions in identical exams given to two classes in successive semester. In only one exam, \#2 in spring 2016 (data in shaded area), narrated video clips were made available to the class.

\begin{tabular}{lccc}
\hline & $\begin{array}{c}\text { Fall 2015; } \mathbf{n}=\mathbf{5 0} \\
\text { mean }( \pm \text { S.D. })\end{array}$ & $\begin{array}{c}\text { Spring 2016; } \mathbf{n}=\mathbf{3 5} \\
\text { mean }( \pm \text { S.D. })\end{array}$ & P value \\
\hline Exam 1 & $71.94( \pm 12.71)$ & $72.58( \pm 13.74)$ & 0.826 \\
Exam 2 & $71.29( \pm 10.39)$ & $77.16( \pm 10.90)$ & 0.014 \\
\hline
\end{tabular}

\section{Results}

\subsection{The Narrated Video Clips}

The data in Table 1 show the performance of the two classes in two exams; the data represent the outcomes from the 27 multiple-choice questions in each exam. In exam 1 both classes had the same preparation; that is, neither class was given access to narrated video clips. The mean scores for the multiple-choice questions in exam 1 were similar and a two-tailed unpaired t-test shows that the mean scores are not statistically different $(\mathrm{P}>0.05)$. This result suggests that there was no statistical difference between the performances of the two classes on this exam. However, when the spring 2016 class was given unlimited access to narrated video clips prior to exam 2, the mean score for the multiple-choice questions in this exam was higher than the score for the previous class. A two-tailed unpaired t-test shows that the mean scores are statistically different $(\mathrm{P}<0.05)$, which suggests that access to narrated video clips improved student performance on this exam. A Z-test analysis showed no significant difference between the two classes on individual questions; however the spring class scored higher than the fall class in 20 questions, worse in 5 and the same in 2 questions.

Statistics tracking through the course website registered the date any narrated video clip was opened by a student in the spring 2016 class; clearly this was not done for the fall 2015 class because no narrated video clips were available. During the spring semester, the class accessed the narrated video clips a total of 1538 times and the accompanying interactive animations 1502 times, which means that each student accessed the video clips and the animations an average of 1.83 and 1.79 times, respectively. Examination of the activity of individuals in the spring 2016 class revealed that not all students accessed every online narrated video clips or animations. However, there was no correlation between access activity and gender, their numerical grade in the exam or their final grade in the course.

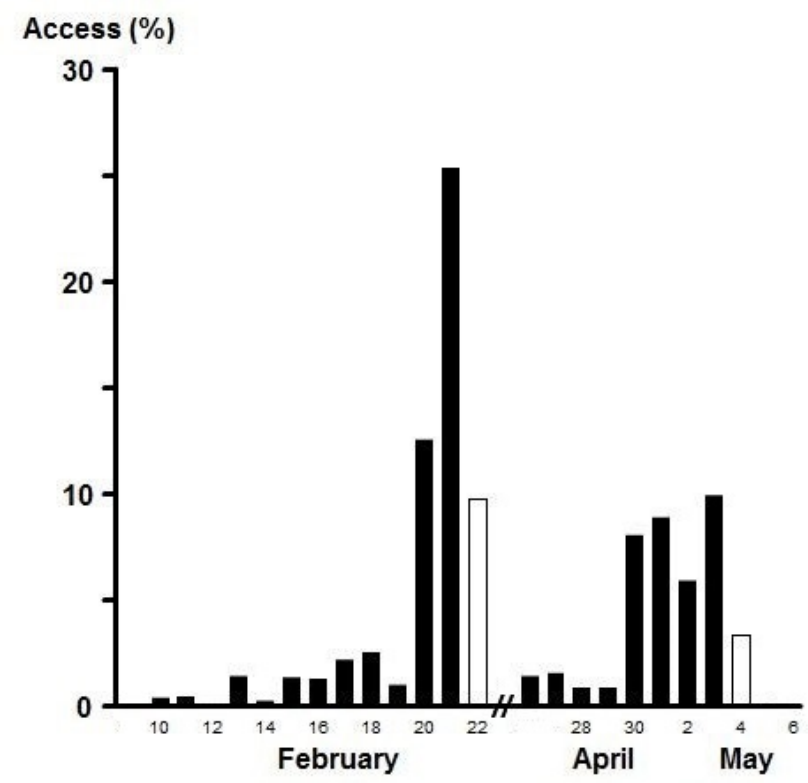

Figure 1. Graph to show the relationship between accesses of the 24 online narrated video clips (expressed as a percentage of the total (1538) hits over time). The two white bars represent data and the dates of the exam (Monday

February $22^{\text {nd }} 2016$ ) and the cumulative exam (Wednesday May $4^{\text {th }} 2016$ ). 
Figure 1 shows the frequency of video clip access during the spring semester 2016. Exam 2 was held was on Monday February $22^{\text {nd }}$ (indicated as the white column towards the center of Figure 1) and the data show that access began about 2 weeks prior to the exam with a gradual increase in the number of hits leading up to the exam. The cumulative exam on Wednesday May $4^{\text {th }}$ (indicated as the white column on the right of Figure 1) showed a similar trend. The number of hits was more consistent in the last 4 days prior to the cumulative exam but there were fewer hits; $58 \%$ of the total hits were recorded on or before exam 2 while $42 \%$ of the total hits were recorded on or before the day of the cumulative exam.

\subsection{The Attitudinal Survey}

Table 2. Results from One Question in the Attitudinal Survey Showing the Reasons Underlying Student Use of the Narrated Video Clips

\begin{tabular}{|c|c|}
\hline \multicolumn{2}{|c|}{$\begin{array}{l}\text { In the majority of circumstances, what was your main reason for } \\
\text { listening to the narrated video clips? }\end{array}$} \\
\hline As a guide to using the animations and simulations. & 17 \\
\hline As a stand-alone mini-lecture. & 13 \\
\hline As a quick reminder of the concept. & 4 \\
\hline As a way to 'cram' immediately before for the exam. & 1 \\
\hline
\end{tabular}

While access to the narrated video clips usually occurred immediately prior to the exams (Figure 1) these data do not indicate student motives behind the use of these online resources. However, results from the attitudinal survey revealed that almost $50 \%$ of the students used the narrated video clips as standalone mini-lectures or as a reminder of a concept. (Table 2), while the same number of students used the clips as a guide to use the animations and simulations. Access data from the learning management system showed that students accessed any one of the 24 animations and simulations at the same rate as the narrated video clip $( \pm 5 \%)$ and Table 3 shows that access to the animations and simulations usually took place after viewing the video clip.

Table 3. Results from One Question in the Attitudinal Survey Showing the Relationship Between Viewing the Narrated Video Clips and Accessing the Animations and Simulations

\begin{tabular}{ll}
\hline \multicolumn{1}{c}{ When did you usually access the interactive animations and simulations? } \\
\hline Immediately after listening to the narrated video clip. & 31 \\
Soon after seeing them in lecture but without first viewing the video clip. & 2 \\
When I saw them on the website but without first viewing the video clip. & 1 \\
At least 24 hours after viewing the video clip. & 1 \\
I did not access the animations and simulations & 0 \\
\hline
\end{tabular}

Figure 2 shows data from questions where students were asked to rank class activities for the value for learning of physiological concepts. Student feedback showed that they considered that the narrated video clips were the most valuable tool for learning concepts, closely followed by lecture and then the interactive animations and simulations (Fig. 2; black columns). When asked about their impressions on the efficiency of these activities for learning, the narrated video clips still ranked highest (Fig. 2; white columns). However, the scores for lectures fell and the interactive animation and simulations increased with the result that the ranking for these two activities was reversed when compared with their value for learning. 


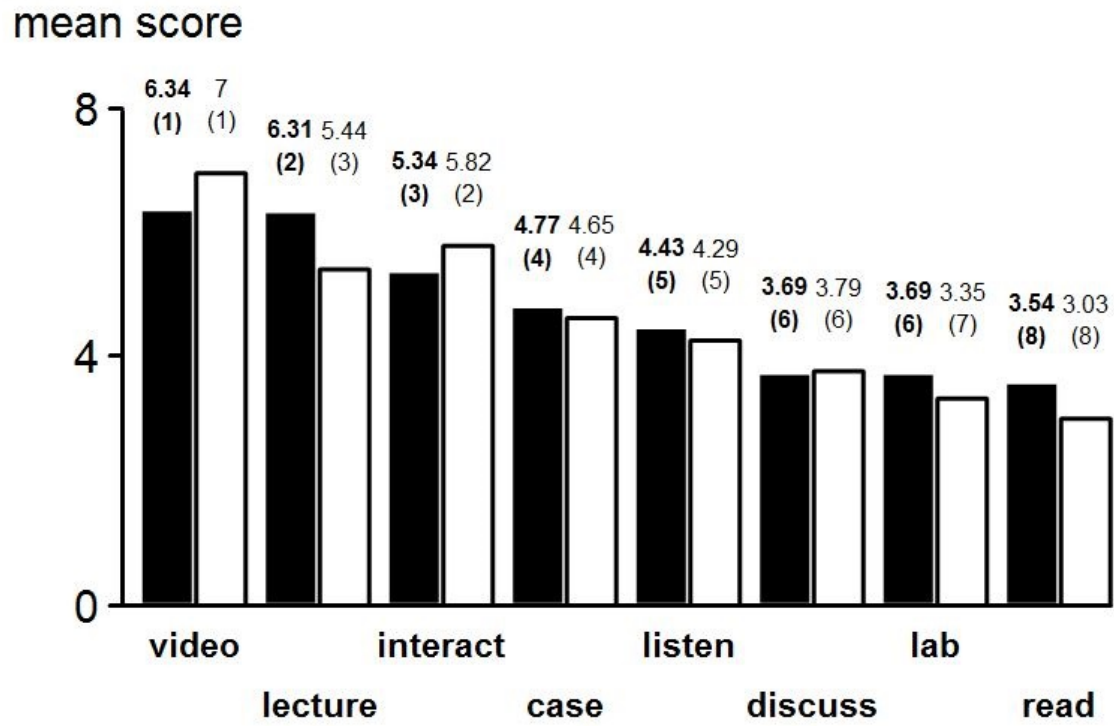

Figure 2. The 35 students in the spring 2016 class were asked to rank (8) activities (shown on the horizontal axis) in the order that they considered was the most valuable for their learning of concepts (black) and the most efficient method for learning concepts (white). In both questions, a first place rank scored 8 points; second place 7 points and so on with the eighth place rank scoring only 1 point. The values above each column represent the mean score (and rank) for the class.

\section{Discussion}

In this study of an undergraduate Animal Physiology course, when two classes of students had the same preparation for an exam their performance was not statistically different (Table 1, Exam 1). This result indicates that the two classes used in this study can be considered to be comparable in their capacity to answer multiple-choice questions. However, when one class (Spring 2016) was given unlimited access to narrated video clips, their answers to multiple-choice questions on a second exam were statistically better than those from the other class (Table 1, Exam 2). This observation shows that these online activities improved the level of student performance on multiple-choice questions. Further, these data indicate that these learning instruments improved learning, and this conclusion was reinforced by data from an attitudinal survey in which students stated that narrated video clips were the best and the most efficient way for them to learn physiology concepts (Fig. 2).

According to Mayer (2001) multimedia instruction makes use of two sensory channels; eyes and ears. The narrated video clips used in this study were developed with this notion in mind, allowing students to watch the animations and hear the synchronized commentary. Thus the narrated video clips permitted students to use both sensory channels at the same time. Following the VARK definition of learning styles (Drago \& Wagner, 2004), the narrated video clips suit aural and visual learners; the latter representing the majority of undergraduate physiology students (Dobson, 2009). Further, all students could use the clips as a guide to subsequent interaction with the animations and simulations (Table 3), a process that may be preferred by kinesthetic learners. Finally, the embedded pause control allowed read/write learners to periodically halt the clips to give these students time to write notes prior to continuing playing the videos.

The data from this study suggest that narrated video clips improve learning, as judged by answers from multiple-choice questions. But what is the basis for this improvement? Instructors may like to think that access to resources that improve students learning and understanding may be sufficient reward in itself. However, it seems possible that the novelty of these available resources may have been enough to encourage students to access the video clips and thus increase the time spent on the material. Unfortunately, the available data only show how many times the students clicked the links, not how long they were engaged with the activity or their attention level. Irrespective of how or why the narrated video clips improved learning, this study shows that these instruments had a positive effect on student exam performance. Perhaps the most disconcerting observation gleaned from this study is the timing of student activities. Students are reminded throughout the course that they should work steadily during the semester because cognitive learning theory maintains that it takes time to transfer new information from working memory to long term memory (Moreno \& Mayer, 1999; Mayer, 2001). However, it is clear from this study that 
students saw the video clips as the most efficient and most valuable means of learning (Fig. 2) and accessed the links just before the exam (Fig. 1). Perhaps this observation explains why a significant number of students used the clips as a quick reminder of a concept or as a mini-lecture (Table 2). Almost $54 \%$ accessed the narrated video clips within 2 days before the exams and $13 \%$ on the day of the exams (Fig. 1), both of which were scheduled for 8 AM. While it is important that learning activities continue to be developed, it seems critical to appreciate the ways they are used and the strategies that can be used to change the student culture away from last minute memorization.

In this study the narrated video clips, the animations and the simulations were used to augment traditional face-to-face instructions. It seems possible that these online resources could be used as intermediate steps between traditional face-to-face lectures, a blended class, a flipped the class (Goldberg, Haase, Shoukas \& Schramm. 2006), and distance learning.

\section{Conclusions}

Unlimited online access to narrated video clips improved student learning, as judged by their performance on multiple choice questions. Students used the video clips as an introduction to interactive animations and simulations and as standalone mini-lectures, yet more than $50 \%$ of the total hits took place with four days of the exam. Students considered the video clips as the best and most efficient way to learn concepts.

\section{Acknowledgements}

The protocols used in the project (15-047) have been reviewed by the IRB at Villanova University and have been deemed exempt. This work was funded by a mini-grant from the Villanova Institute for Teaching and Learning, summer 2015. The author wishes to thank Dr. Carol A Weiss for her constant encouragement and tireless discussions during all phases of this project.

\section{References}

Clark RC., \& Mayer RE. (2003). E-Learning and the science of instruction: proven guidelines for consumers and designers of multimedia learning. Jossey-Bass/Pfeiffer.

Dobson JL. (2009). Learning style preferences and course performance in an undergraduate physiology class. Adv in Physiol Edu., 33(4), 308-314.

Drago WA., \& Wagner RJ. (2004). VARK preferred learning styles and online education. Management Research News, 27, 1-13. https://doi.org/10.1108/01409170410784211

Goldberg HR., Haase E., Shoukas A., \& Schramm, L. (2006). Redefining classroom instruction. Adv in Physiol Edu., 30, 124-127. https://doi.org/10.1152/advan.00017.2006

Knight JK., \& Wood WB. (2005). Teaching more by lecturing less. Cell Biol Edu., 4, 298-310. https://doi.org/10.1187/05-06-0082

Kozma RB. (1991). Learning with media. Review of Educational Research, 61(2), 179-212. https://doi.org/10.3102/00346543061002179

Lujan HL., \& DiCarlo SE. (2005). Too much teaching, not enough learning: what is the solution? Adv in Physiol Edu., 30, $19-22$.

Mayer. (2001). RE Multimedia learning. New York: Cambridge University Press. https://doi.org/10.1017/CBO9781139164603

Moreno R., \& Mayer RE. (1999). Cognitive principles of multimedia learning: The role of modality and contiguity. Journal of Educational Psychology, 91, 358-368. https://doi.org/10.1037/0022-0663.91.2.358

Sweller J. (2005). Implications of Cognitive Load Theory for Multimedia Learning. In: Handbook of Multimedia Learning. New York: Cambridge University Press. https://doi.org/10.1017/CBO9780511816819.003

Wehrwein EA., Lujan HL., \& DiCarlo SE. (2007). Gender differences in learning style preferences among undergraduate physiology students. Adv in Physiol Edu., 31, 153-157. https://doi.org/10.1152/advan.00060.2006 
Appendix 1: Samples of narrated video clips and interactive animations/simulations:

1. Nernst Equation: changing ion levels:

video clip: http://www10.homepage.villanova.edu/phil.stephens/Nuggets/part1/ChangeIonNernst/nernst.html animation/simulation:

http://www10.homepage.villanova.edu/phil.stephens/Nuggets/part1/ChangeIonNernst/index.html

\section{Presynaptic Events}

video clip:

http://www10.homepage.villanova.edu/phil.stephens/Nuggets/part1/presynaptic/index.html animation/simulation:

http://www10.homepage.villanova.edu/phil.stephens/Nuggets/part1/presynaptic/index.html

\section{Cyclic AMP}

video clip:

http://www10.homepage.villanova.edu/phil.stephens/Nuggets/part1/cyclicAMP/index.html animation/simulation:

http://www10.homepage.villanova.edu/phil.stephens/Nuggets/part1/cyclicAMP/index.html 